\title{
Rethinking the theory of evolution: New perspectives on human evolution and why it matters for Theology
}

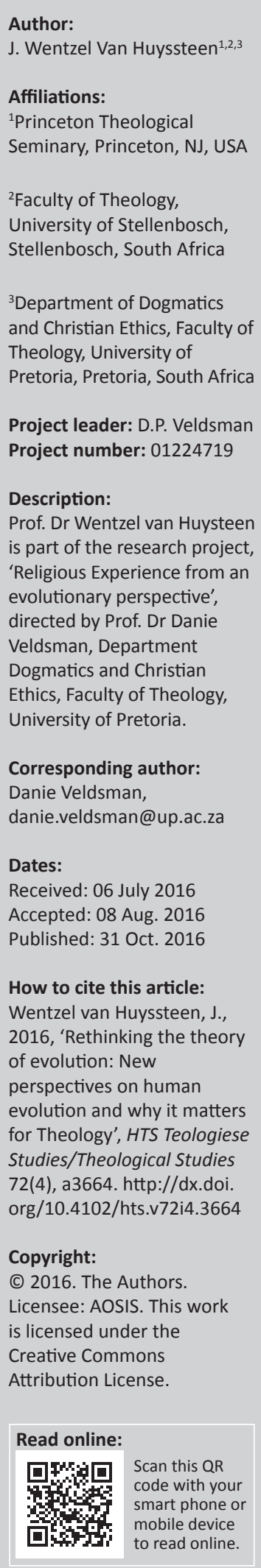

This article addresses the issue of human imagination from the perspective of 'niche construction' in the wider discussion about 'what makes us human' and what it means to be a 'self', specifically for the Christian faith and for theology. In the article, a brief review of human origins and human evolution demonstrates the path and substantive impact of changes in behaviour, life histories and bodies in our human ancestors and us as humans ourselves. In the interactive process of niche construction, potentially changeable natural environments were, and are, acting continuously on variation in the gene pools of populations, and in this way gene pools were modified over generations. It is argued that a distinctively human imagination is part of the explanation for human evolutionary success and can be seen as one of the structurally significant aspects of the transition from earlier members of the genus Homo to ourselves as we are today. There is thus a naturalness to human imagination, even to religious imagination, that facilitates engagement with the world that is truly distinct. This provides fruitful addition to the toolkit of inquiry for both evolutionary scientists and interdisciplinary theologians interested in reconstructing the long, winding historical path to humanity.

\section{Introduction}

Today, and not surprisingly, scholars from numerous and highly diverse fields are not only addressing the question of 'what makes us human' and what it means to be a 'self', but are also trying to discern what it might mean for the Christian faith and for theology. These questions do not only pertain to empirical questions about what distinguishes humans from their hominid ancestors, but they often also refer to a very different kind of question, namely, which of our specific peculiarities give us humans our distinctive 'species specificity' and significance? What is interesting is that this question is specifically not only empirical, because we humans in a sense actually draw the hominin-human boundary in ways that are also determined by our cultural contexts (cf. Cartmill \& Brown 2012:182). One popular way of defining human distinctiveness is, of course, to make a clear distinction between anatomical and behavioural differences.

\section{Defining humanness}

The meaning, the markers and the justification of human identity and status have, of course, fluctuated throughout Western academic history. Generally, of course, language has been viewed as a crucial marker (cf. Botha \& Everaert 2013) Deacon 1997; Mellars 1989, 1991; Mithen 1996; Noble \& Davidson 1996; Tattersall 1998, 2002). Furthermore, conceptions of defining humanness have lately shifted towards our capacity for 'prosociality', which we share with primates, as well as our unique propensity for imitation (cf. Cartmill \& Brown 2012:182). Also music (Mithen 2009), sexuality and empathy (Boehm 2012; De Waal 2006, 2009; Sheets-Johnstone 2008) are in the process of being thoroughly researched and hailed as the foundation of not only language, social norms and morality, but also symbolic and even religious behaviour.

Another genuinely panhuman trait is the remarkable human capacity for seeing things from someone else's perspective, generally known as theory of mind. Humans are indeed strongly disposed for intuitively understanding the motivations of others - so much so that we often see motivations where they do not exist (cf. Cartmill \& Brown 2012:182). This unique ability does, however, give us adaptively valuable insights into the intentions of our friends, enemies, predators and prey. For scientists such as Águstin Fuentes (cf. 2009) and Richard Potts (cf. 1996, 2012), the real success of humans as a species can be attributed largely to our tendency and capacity for extreme alteration of the world around us. We not only construct material items but also engage

Note: Original Research: Volume 17 in the South African Science and Religion Forum Series, edited by Prof. Dr Cornel du Toit (UNISA) and Prof. Dr Danie Veldsman, entitled 'Creation, Consciousness and Christology: Evolutionary Perspectives', papers presented at the 20th conference of the South African Science and Religion Forum (SASRF) of the Research Institute for Theology and Religion held at the University of South Africa, Pretoria 16-18 September 2015. 
in the creation and navigation of social and symbolic structures, space and place, in a manner unequalled by other organisms. Most anthropologists would agree that human identity should be seen as interactively constructed by, and involved in the construction of, a conflux of biological, behavioural, social and symbolic contexts (cf. Fuentes 2009:12). The problem is that even anthropologists (like many theologians) often refuse to acknowledge a significant role for biological features and biological histories (evolution) in human action, sensation and engagement.

Importantly, some evolutionary anthropologists actually now find the distinction 'Darwinian' and 'Neo-Darwinian' unhelpful for many of the current evolutionary theories of interest, and argue that we should recognise that there is an expansive body of research and theory that is not captured by these headings anymore (cf. Fuentes 2009:12). Basic Darwinian theory prioritises natural selection and sexual selection as the prime factors in evolutionary change and the emergence of adaptations. ${ }^{1}$

Without discounting the important role of natural and sexual selection in biological systems, some anthropologists want to emphasise that scientists are now expanding on Darwin's contributions and invite us to focus on more recent, emerging trends in evolutionary theory. Famously, of course, already in a 1983 landmark essay, Richard Lewontin pointed the way forward to a more revolutionary and interactionist view of the process of evolution (cf. Lewontin 1983). Lewontin started out by pointing to the general, accepted view that the modern theory of evolution is often seen as a fusion or synthesis of the two great insights of the 19th century biology: Darwin's realisation that the variation amongst species arises from the conversion of variation between individuals within species (adaptation) and Mendel's discovery of discrete factors as the basis for the inheritance of differences between individuals (genes). The general belief is indeed that the immense progress made in biology in the 20th century, and now in the 21st century, rests firmly on these two major discoveries of the previous time (cf. Lewontin 1983:273). In a fascinating analysis, Lewontin then goes on to show how these very same developments served to keep us locked into a rigid framework of thought about the development and evolution of organisms: from the very source of Mendel's and Darwin's success as biologists, the way that soon internal forces (cf. genes) were separated from external forces (environment or adaptation), flows the conviction that genes are regarded as the cause of organisms (Mendel), while the external world, the environment, acts on the organism and causes the form of organisms (Darwin). It is, however, this very distinction that causes some of the most serious problems for evolutionary biology.

1.Natural selection is generally seen as the process by which certain phenotypes (e.g. morphology and behaviour) that are most effective in reproducing themselves (and thus their genetic basis or genotype) in a given environment become more frequent in a population across generations. Sexual selection is the over-representation of specific phenotypes across generations as a result of mate choice and/or intrasexual competition. Those traits that lead to the success of particular phenotype and become the predominant traits in subsequent generations are termed 'adaptations'. These traits, and the individual possessing them, are then said to be more 'fit'. And it is these 'fit' phenotypes that will strive for optimality and will rise to a majority status within the population over evolutionary time (cf. Fuentes 2009:12).

\section{Moving beyond Darwinism}

In Darwinism, through time, the living organism was seen as the interaction of two causal sequences: internal forces produced the variation amongst organisms, while autonomous external forces moulded the species on the basis of these autonomous internally caused variations (cf. Lewontin 1983:273). Therefore, the essence of Darwin's account of evolution was seen as the separation of causes of ontogenetic variation, as coming from internal factors, and phylogenetic variation, imposed from the external environment by way of internal selection. Lewontin was quick to point out, however, that as time passed, Mendel's view of organisms as the manifestation of autonomous 'factors' (genes) with their own laws, and Darwin's view of organisms as passive objects moulded by the external force of natural selection, increasingly contradicted with the known facts of development and population biology (cf. Lewontin 1983:275).

Indeed, anyone interested in the development of evolutionary biology should be concerned about two issues about the forms of organisms. The first is the ontogenetic process by which the sequence of forms that comprise an individual's life history comes into being. The second is the phylogenetic process by which the species as collective entities form and change on the basis of variation amongst the individuals that make up them. Classical, post-Darwinian and postMendelian biology has, indeed, settled on two metaphors through which these processes are seen. The first metaphor (ontogenetic process) is seen as the unfolding of a form, already latent in the genes, requiring only an original triggering at fertilisation and an environment adequate to allow 'normal' development to continue; the second metaphor (phylogenetic process) is seen as problem and solution. The environment 'poses the problem', and the organisms 'posit solutions', of which the best is finally 'chosen'. Lewontin then set out to show that these two Mendelian and Darwinian metaphors are in fact wrong: individual development is not just an unfolding, and evolution is not a series of solutions to present and solve problems. Rather, genes, organisms, and environments are in reciprocal interaction with each other in such a way that each is both cause and effect in a quite complex way. The known facts of development and of natural history make it patently clear that genes do not determine individuals nor do environments determine species (cf. Lewontin 1983:276).

What various biologists have shown is, in fact, the reciprocity of effects of genetic state on environmental sensitivity, and of the environmental state on genetic sensitivity of the developing organism (cf. Lewontin 1983:278). On this view, the final step is to incorporate the organism as itself a cause in its own development as a mechanism by which external and internal factors influence its future. Therefore, to describe phenotype as the consequence of gene, environment and contingent 'accident' leaves out of account entirely the element of temporal order that is the essence in a developmental process (cf. Lewontin 1983:279). The organism is not simply the object of developmental forces, but the subject of those 
forces as well. In this sense, organisms as entities are one of the causes of their own development (cf. Lewontin 1983:279). What we find here also is a far more nuanced view of adaptation itself: the environments of organisms are made by the organisms themselves as a consequence of their own life activities. In this sense, one can even say that organisms do not just 'adapt' to their environments, but they construct them out of bits and pieces of the external world, thus implying that organisms determine what is relevant as they construct their environment, and organisms alter the external world as it becomes part of their environments (cf. Lewontin 1983:280f).

Clearly, then, the metaphor of construction rather than adaptation leads to a different formulation of natural selection and evolution as such. In fact, on a constructionist view, organisms and environment coevolve, each as a function of the other (cf. Lewontin 1983:282). The profound implication of this is that the coevolution of organism and environment are not arbitrary forms of evolution but are constrained, which explains the phenomenon of convergence: some pathways through the organism-environment space are more probable than others precisely because there are real physical relations in the external world that constrain change (cf. Lewontin 1983:283). Organisms, then, make and are made by their environment in the course of phylogenetic change, just as organisms are both the causes and consequences of their own ontogenetic development. On Lewontin's transfigured view of Darwinian evolution, then, this means the study of evolution does not have to lean so heavily anymore on an impoverished view of the relation between gene, environment and organism (cf. Lewontin 1983:284).

Also evolutionary anthropologist Christopher Boehm, for instance, has very recently pointed out how clearly Charles Darwin always implied that potentially changeable environments are continuously acting on the gene pool with significant results for evolutionary development and even speciation (cf. Boehm 2012:3f.). At the heart, then, of Darwin's project we already find what evolutionary biologists and anthropologists today are calling a process of niche construction: in a remarkable interactive process, potentially changeable natural environments were, and are, acting continuously on variation in the gene pools of populations, and in this way gene pools were modified over generations.

\section{Moving into niche construction}

In discussing equations that describe and explain this kind of coevolution of both organism and environment, Mühling has recently pointed out that both in fact function alike as causes as well as effects, and that on this view the traditional unidirectional character of evolutionary theory is abandoned (cf. Mühling 2014:144ff.). Relying on an analysis of Lewontin's classical essay (cf. Lewontin 1983), scientists such as John Odling-Smee, Kevin Laland and Marcus Feldman have proposed that classical evolutionary theory has to be expanded in such a way that the new theory can satisfy the new demands resulting from the work of Lewontin and others (cf. Olding-Smee et al. 2003). This is only possible when niche construction is not viewed as another given fact of nature readily explainable by classical Neo-Darwinism, but only if niche construction itself is in fact seen as an additional mechanism of evolution working at the very same basic level as natural selection (cf. Mühling 2014:145). ${ }^{2}$

Niche construction thus occurs when an organism modifies the relationship between itself and its environment by actively changing one or more of the factors in its environment, and thus also potentially in itself. These definitions are more than just mere definitions, because they do indeed provide a new mechanism additional to natural selection. And Mühling is right: by doing so, niche construction broadens NeoDarwinism in another respect as well - classical NeoDarwinism knows only one inheritance system, namely, the genetic system: the genetic pool alone plays the role of a system of transferring information over time. But niche construction now clearly has the consequence that information can be transferred in additional ways too, one of which, according to Olding-Smee et al., is called environmental or ecological inheritance (cf. Mühling 2014:147).

It is, however, especially Jablonka and Lamb's important work, Evolution in Four Dimensions (2005), that has called for the renewal of evolutionary theory by arguing for 'evolution in four dimensions' rather than for a focus on just one, namely, the genetic. Jablonka and Lamb's basic claim is that biological thinking about heredity and evolution is undergoing a revolutionary change and what is emerging is a new synthesis that challenges the classic gene-centred view of new-Darwinism that has dominated biological thought for the last 50 years. In addition to genetics as an important inheritance system, Jablonka and Lamb argue for three other inheritance systems that also have causal roles in evolutionary change. These three systems are the epigenetic, behavioural and symbolic inheritance systems. Epigenetic inheritance ${ }^{3}$ is found in all organisms, behavioural inheritance ${ }^{4}$ is found in most organisms and symbolic inheritance occurs only in humans (cf. Fuentes 2009:13; Jablonka \& Lamb 2005:1-8). According to this view, there is more to heredity than genes, some acquired information is inherited and evolutionary change can thus result from instruction as well as from selection. This constructivist view moves beyond standard NeoDarwinian approaches and acknowledges that many organisms transmit information via behaviour, thus stating that acquisition of evolutionarily relevant behavioural patterns can occur through socially mediated learning, exactly what Boehm has argued recently. Symbolic inheritance, of course, comes with language and the ability to

2.See Mühling (2014:144-149) for categories, principles and definitions of "niche construction'

3.On a cellular level, epigenetic differences are the consequences of events that occurred during the developmental history of each type of cell that determined which genes are turned on, and how they act and interact. Thus, although their DNA sequences remain unchanged during development, cells nevertheless acquire information that they can pass on to their progeny. This information is transmitted information that they can pass on to their progeny. This information is transmitted second dimension of heredity and evolution (cf. Jablonka \& Lamb 2005:113).

4. Here Jablonka and Lamb argue that the capacity to learn has indeed evolved genetically, but learning itself is now also recognised as an agent of evolutionary change (cf. Jablonka \& Lamb 2005:155ff.). Therefore, cultural evolution in animals, change (cf. Jablonka \& Lamb 2005:155ff.). Therefore, cultural evolution in animals,
and thus in humans, can be complex, gradual and cumulative, and involve several different aspects of behaviour (cf. Jablonka \& Lamb 2005:180). 
creatively engage in information transfer that can be complex and contain a high density of information. What makes the human species so different and so special, and what makes us human, lies in the way we can organise, transfer and acquire information. It is, therefore, our ability to think and communicate through words and other types of symbols that makes us a fundamentally different kind of niche constructor. On this view, then, rationality, linguistic ability, artistic ability, the moral sense and religiosity are all facets of symbolic thought and communication (cf. Jablonka \& Lamb 2005:193-231). ${ }^{5}$

On this view, although it is clear that the symbolic system of acquiring and transmitting information has properties that it shares with other inheritance systems, it is also clearly different from any of them. Jablonka and Lamb thus argue convincingly that human cultural evolution, which is based largely on information transmitted through symbolic communication, has characteristics that make it very different from other types of biological evolution (cf. Jablonka \& Lamb 2005:155f.). Their view of human behaviour and cultural evolution also clearly differs from the classical NeoDarwinian view and the question 'how a cultural entity or behaviour has been selected for and who benefits from it?'. On the contrary, the focus here is as follows: in order to understand why a particular cultural entity exists or changes, one has to consider its origin, its reconstruction and its functional preservation. Thus, the following question is implied: why a new behaviour or idea is generated, how it develops and how it is finally passed on? On this view, then, cultural evolution can clearly not be explained in purely NeoDarwinian terms. To understand how and why cultures change, we need a far richer concept of the environment that is traditionally used in Darwinian theory. It is therefore necessary to recognise that the environment has an interactive role in the generation of cultural traits and entities, as well as their selection and construction (cf. Jablonka \& Lamb 2005:222f.).

On this view, there clearly is much more to evolution than simply the inheritance of genes. Moreover, and importantly, this interactionist perspective blurs any clear prioritisation in inheritance systems and, thus, requires a clear move away from approaches that are limited to either social or biological focuses. On this view, 'evolution as interactive construction' is the idea that evolution is never only a matter of biologically developing organisms, but also a matter of organismenvironment systems interacting and changing over time in a dynamic interactive process of niche construction as a significant evolutionary force alongside natural selection (cf. Fuentes 2009:14; also Ruse 2012:125). ${ }^{6}$ For an understanding

5.This makes clear that the symbolic system, the peculiar human-specific way of thinking and communicating, may have exactly the same basic neural underpinnings as information transmission in other animals, but the nature of the communication (with the self and with others) is not the same (cf. Jablonka \& Lamb 2005:194).

6.In this synergistic interaction between organisms and their environment, niche construction emerges as inherently a constructivist process in which biological, ecological and social/cultural spheres not only interact but also provide a model for human genetic and cultural evolution by incorporating three levels or dimensions: genetic processes, ontogenetic processes and cultural processes (cf. Fuentes genetic proce
2009:14). of human evolution, this is obviously extremely important: most anthropologists would agree that humans are constructed by, and involved in the construction of, contexts that are simultaneously physiological, behavioural, historical, social and symbolic. In this sense, human behavioural evolution must be seen primarily as a system evolving, rather than a set of independent or moderately connected traits evolving (cf. Fuentes 2009:15). On this view, niche construction is a core factor in human behavioural evolution. The startling conclusion, however, is that we should consider the potential impacts of a diverse array of processes that affect inheritance and evolutionary change, and the possibility that natural selection can occur at multiple levels and may not always be the only, or main, driver of change (cf. Fuentes 2009:16).

At the heart of this then is the increasingly rapid and dynamic niche construction by humans - which I will argue is the biological ground for symbolic behaviour - particularly as it relates to aspects of cognitive and symbolic function and social relationships, and the imaginative ability to deploy multiple modes of responding to evolutionary pressures. Fuentes is here in agreement with Deacon (1997), Donald (2001), King (2007), Barnard (2012) and Robinson (2010), that is, it is our place as a semiotic species, and the use of symbol as a core infrastructure of our perceptions in our perceptions of, and dealing with the world, that act as a major factor, and thus as a hallmark of human evolution (cf. Fuentes 2014:12).

Humans have an imagination that is part of our perceptual and interactive reality and is a substantive aspect of lived experience. Thus, it is realistic to accept that at some point in the last 400000 years language and hyper-complex intentionality acted to 'lock-in' the more-than-material as our permanent state of being, and so laid the groundwork for the evolution of morality, the possibility of metaphysics, aesthetic propensities, religious imagination and the propensity for religious belief (cf. van Huysteen 2006), as crucial parts of the uniquely human experience. Now existing in a landscape where the material and social elements have semiotic properties, and where communication and action can potentially be influenced by representations of both past and future behaviour, implies the possession of an imagination, and even something like 'hope', that is, the expectation of future outcomes beyond the predictable (cf. Fuentes 2014:13). The assertion here is that this interactive process occurs as a component of the human niche as it moves dynamically through the Pleistocene as part of the emerging human toolkit.

Importantly, imagination, and therefore religious imagination, on this view is not only an exaptation, a spurious by-product of evolution, but it is also crucial to the process of human evolution and incorporates behavioural processes and a sense of imagination and hope that would, and did, increase the likelihood of innovation and successful responses to evolutionary challenges (cf. Fuentes 2014:14). This also implies that human distinctiveness may have emerged not merely through the ascent of a hierarchy of semiotic competence, of which symbolic competence was the pinnacle, but through the 
entering of what Andrew Robinson refers to as the semiotic matrix (cf. Robinson 2010:150f.). In the Upper Paleolithic in Europe, and probably earlier in Africa (cf. van Huysteen 2006:217-270), anatomically modern humans crossed a new cognitive threshold into a semiotic realm, a threshold of semiotic competence that allowed for the combination of remarkable new forms of symbolic and, thus, religious communication.

\section{Conclusion}

This brief review of human origins and human evolution demonstrates the path and substantive impact of changes in behaviour, life histories and bodies in our human ancestors and us humans ourselves. From this, it is clear that patterns that in the Upper Paleolithic would lead to the unambiguous appearance of 'art' and 'symbol' now also combined with the evolution of empathy and compassion and the deep caring for others (cf. Boehm 2012; Fuentes 2014; van Huysteen 2014). It should therefore not be surprising that a distinctively human imagination is part of the explanation for human evolutionary success and can be seen as one of the structurally significant aspects of the transition from earlier members of the genus Homo to ourselves as we are today.

For Christian theologians, this provides an exciting bottomup view of the spectacularly complex way in which God has shaped and prepared our species to be physically, mentally and spiritually 'ready' for religious belief and faith. I believe that my original intuition that there is a naturalness to human imagination, and even to religious imagination (cf. van Huysteen 2006), which facilitates engagement with the world that is truly distinct, thus becomes more plausible. In Fuentes' words: if this is indeed that case, it provides a small and hopefully fruitful addition to the toolkit of inquiry for both evolutionary scientists and interdisciplinary theologians interested in reconstructing the long, winding historical path to humanity (Fuentes 2014:18).

\section{Acknowledgements Competing interests}

The author declares that he has no financial or personal relationships which may have inappropriately influenced him in writing this article.

\section{References}

Barnard, A., 2012, Genesis of symbolic thought, Cambridge University Press, Cambridge. Boehm, C., 2012, Moral origins: The evolution of virtue, altruism, and shame, Basic Books, New York.

Botha, R. \& Everaert, M.B.H., 2013, The evolutionary emergence of language: Evidence and inference, Oxford University Press, Oxford.

Cartmill, M. \& Brown, K., 2012, 'Being human means that "Being Human" means whatever we say it means', in J.M. Calcagno \& A. Fuentes (eds.), What makes us human? Answers from evolutionary anthropology', Evolutionary Anthropology 21, 183.

Deacon, T., 1997, The symbolic species: The co-evolution of language and the brain, Norton, New York.

De Waal, F., 2006, Primates and philosophers: How morality evolved, Princeton University Press, Princeton, NJ.

De Waal, F., 2009, The age of empathy: Nature's lessons for a kinder society, Three Rivers Press, New York.

Donald, M., 2001, A mind so rare: The evolution of human consciousness, W.W. Norton, New York.

Fuentes, A., 2014, 'Human evolution, niche complexity, and the emergence of a distinctly human imagination', Time and Mind 7(3), 241-257.

Jablonka, E. \& Lamb, M., 2005, Evolution in four dimensions: Genetic, epigenetic, behavioral, and symbolic variation in the history of life, MIT Press, Cambridge, MA.

King, B., 2007, Evolving God: A provocative view on the origins of religion, Doubleday, New York.

Lewontin, R.C., 1983, 'Gene, organism, and environment', in D.S. Bendall (ed.), Evolution from mice to men, pp. 273-285, Cambridge University Press, Cambridge, MA.

Marks, J., 2010, 'Off human nature', American Anthropologist: Vital Forum 112(4), 512.

Mellars, P., 1989, 'Major issues in the emergence of modern humans', Current Anthropology 30(3), 349-385. http://dx.doi.org/10.1086/203755

Mellars, P., 1991, 'Cognitive changes and the emergence of modern humans in Europe', Cambridge Archeological Journal 1(1), 63-76. http://dx.doi.org/10.1017/ S0959774300000251

Mithen, S., 1996, The prehistory of the mind: A search for the origins of art, religion, and science, Thames and Hudson, London.

Mithen, S., 2009, The singing Neanderthals: The origins of music, language, mind, and body, Harvard University Press, Cambridge, MA.

Mühling, M., 2014, Resonances: Neurobiology, evolution and theology. Evolutionary niche construction, the ecological brain and relational-narrative theology, Vandenhhoeck \& Ruprecht, Gottingen.

Noble, W. \& Davidson, I., 1996, Human evolution, language and mind: A psychological and archaeological inquiry, Cambridge University Press, Cambridge, MA.

Olding-Smee, F.J., Laland, K.N. \& Feldman, M.W., 2003, Niche construction: The neglected process in evolution, Princeton University Press, Princeton, NJ.

Potts, R., 1996, Humanity's descent, Morrow, New York.

Potts, R., 2012, 'Environmental and behavioral evidence pertaining to the evolution of early homo', Current Anthropology 53(suppl. 6), 299-317.

Robinson, A., 2010, God and the world of signs: Trinity, evolution, and the metaphysical semiotics of C.S. Pierce, Brill Publishers, Boston, MA.

Ruse, M., 2012, The philosophy of human evolution, Cambridge University Press, Cambridge, MA.

Tattersall, I., 1998, Becoming human: Evolution and human uniqueness, Hartcourt Brace, New York.

Tattersall, I., 2002, The monkey in the mirror: Essays on the science of what makes us human, Hartcourt, New York.

Van Huyssteen, J.W., 2006, Alone in the world: Human uniqueness in science and theology, William B. Eerdmans, Grand Rapids, MI.

Van Huyssteen, J.W., 2014, 'From empathy to embodied faith: Interdisciplinary perspectives on the evolution of religion', in F. Watt \& L. Turner (eds.), Evolution, religion, and cognitive science: Critical and constructive essays, pp. 132-151, Oxford University Press, Oxford. 